\title{
4D Sonography in Assessment of Fetal Neurobehavior
}

\author{
Toshiyuki Hata, Miki Sato, Kenji Kanenishi, Uiko Hanaoka, Hirokazu Tanaka
}

\begin{abstract}
'Observation of fetal behavior reflects the functioning of the central nervous system, and behavioral assessment of the fetus enables the function of the brain to be examined'. ${ }^{1}$ The introduction of four-dimensional (4D) sonography techniques would facilitate fetal behavioral assessment in three dimensions in real time during pregnancy. We describe the latest 4D sonographic studies on fetal neurobehavior in all three trimesters of pregnancy. 4D sonography also facilitated the evaluation of interhuman contact and intrapair stimulation in twin pregnancies in utero. This novel technique may assist in the evaluation of fetal neurobehavior and intertwin contact and intrapair stimulation and offer potential advantages relative to conventional two-dimensional sonography. 4D sonography may become an important modality in future research on fetal neurobehavioral development and the prenatal identification of severely brain-damaged infants.
\end{abstract}

Keywords: 4D sonography, Fetal neurobehavior, Intertwin contact, Intrapair stimulation, Singleton pregnancy, Twin pregnancy.

How to cite this article: Hata T, Sato M, Kanenishi K, Hanaoka $U$, Tanaka H. 4D Sonography in Assessment of Fetal Neurobehavior. Donald School J Ultrasound Obstet Gynecol 2012;6(2):121-131.

\section{Source of support: Nil}

Conflict of interest: None declared

\section{INTRODUCTION}

'Behavior is a product of the functioning central nervous system and hence, by studying behavior, it is possible to make inferences about the functioning of the brain. By observing the behavior of the fetus, it is possible to examine the functioning of the central nervous system and brain and this provides, for the first time in the fetus, a 'direct' means to assess arguably the most important organ we possess'. ${ }^{1}$ Fetal behavioral patterns have been considered as indicators of fetal brain and central nervous system development. ${ }^{2,3}$ 'Analysis of fetal behavior in comparison with morphological studies had led to the conclusion that fetal behavior patterns directly reflect developmental and maturational processes of the fetal central nervous system'. ${ }^{4}$

Numerous studies employing conventional twodimensional (2D) ultrasound have shown that normally developing fetuses and fetuses at risk exhibit different patterns of behavior. ${ }^{5-15}$ However, there are some limitations for assessing fetal movements employing conventional 2D sonography. 'Because of the 2D character of real-time scanning, fetal movements outside the scanning plane cannot be displayed on the monitor screen' ${ }^{16}$
'Three-dimensional (3D) sonography has the potential to provide improved visualization of fetal anatomic morphology compared with conventional 2D sonographic imaging. ${ }^{17}$ 'Because of its 3D imaging capabilities, 3D sonography should be superior to $2 \mathrm{D}$ sonography for the assessment of fetal movements'. ${ }^{16}$ With the appearance and development of four-dimensional (4D) sonography, fetal behavioral movements and the full range of facial expressions can be observed. ${ }^{4,18-28}$ The ease with which 4D sonography can be used to evaluate fetal movements might well promote a resurgence of interest in fetal behavior and responsiveness. ${ }^{29}$

'Fetal behavior, defined as any observable action or reaction to an external stimulus by the fetus, reflects the activity of the fetal central nervous system' 1,3 'It is assumed that endogenous motility and reactions towards stimuli are expressions of early neuromuscular development and act on the differentiation of the neuromuscular system, ${ }^{30}$ The existence of intrapair stimulation per se in twin pregnancies could provide important clues regarding the functioning of tactile and proprioceptive sensitivity, which are impossible to ascertain with an intact single fetus. ${ }^{31}$ Fetal behavior in twins is an interesting topic and a challenge for both anthropological and medical researchers. ${ }^{30}$ However, fetal behavior in twin pregnancies has been insufficiently studied. ${ }^{31}$

The present paper reviews 4D sonographic studies on fetal neurobehavior, and intertwin contact, and, on this basis, makes recommendations for future research on fetal neurobehavioral development and intrapair stimulation in twin pregnancies.

\section{FIRST AND EARLY SECOND TRIMESTERS}

'Visualization of the entire fetal body by $4 \mathrm{D}$ sonography is limited before 20 weeks of gestation (although it depends on the defined region of interest) because the viewing area is limited to that of the 4D probe ${ }^{, 17}$ (Figs 1 and 2). Kurjak et $\mathrm{al}^{32}$ used $4 \mathrm{D}$ sonography to study 98 normal embryos and fetuses aged from 6 to 12 weeks, and found that body and limb movements can be visualized a week earlier than with 2D sonography. Three types of movement could be visualized in the first trimester: Gross body movements between 7 and 8 weeks, limb movements after 10 weeks, and complex limb movements after 11 weeks of gestation. These researchers concluded that body and limb movements assessed by 4D sonography can be visualized a week earlier 


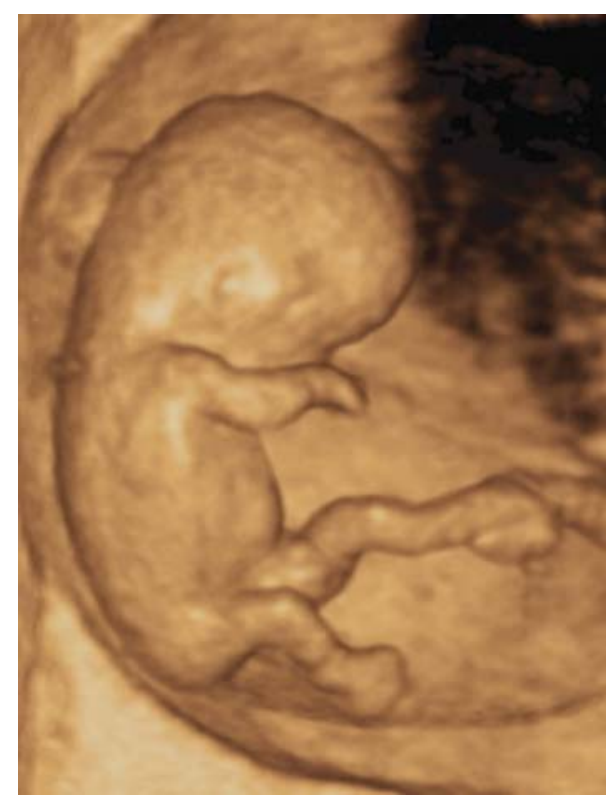

Fig. 1: 4D sonographic image of 10-week fetus

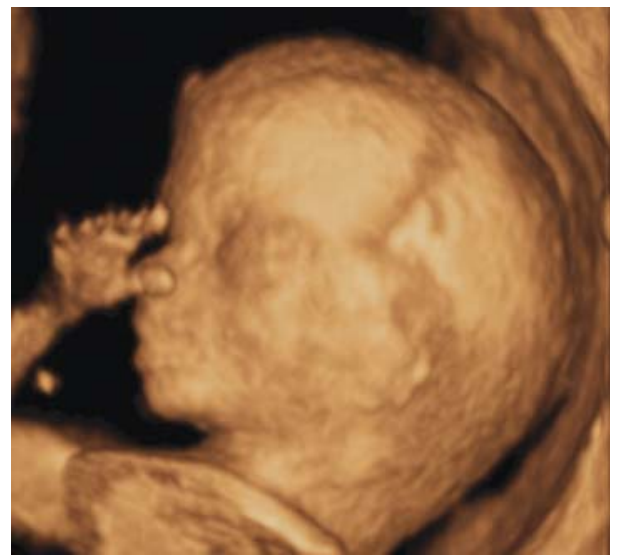

Fig. 2: 4D sonographic image of the fetal face at 13 weeks and 4 days of gestation

than with conventional 2D sonography. In another study by this group, 100 women with normal singleton pregnancies were recruited for longitudinal 4D sonographic examination to evaluate fetal neurodevelopmental parameters from the 7 th to 14 th weeks. ${ }^{33}$ The measurements of seven parameters (general movements, stretching, isolated arm and leg movements, head retroflexion, head rotation and head anteflexion) were correlated with the gestational age and these parameters showed an increasing frequency of fetal movement during the first trimester. However, the frequency of a startle pattern did not correlate with gestation in the first trimester. Moreover, Kurjak et $\mathrm{al}^{34}$ measured the incidence of fetal movement patterns for 30 minutes with 35 fetuses between 8 and 14 weeks of gestation and observed the highest incidence of general movements. Yigiter and Kavak ${ }^{35}$ also used 4D sonography to investigate 13 normal fetuses at 11 and 14 weeks of gestation and noted a tendency toward an increased

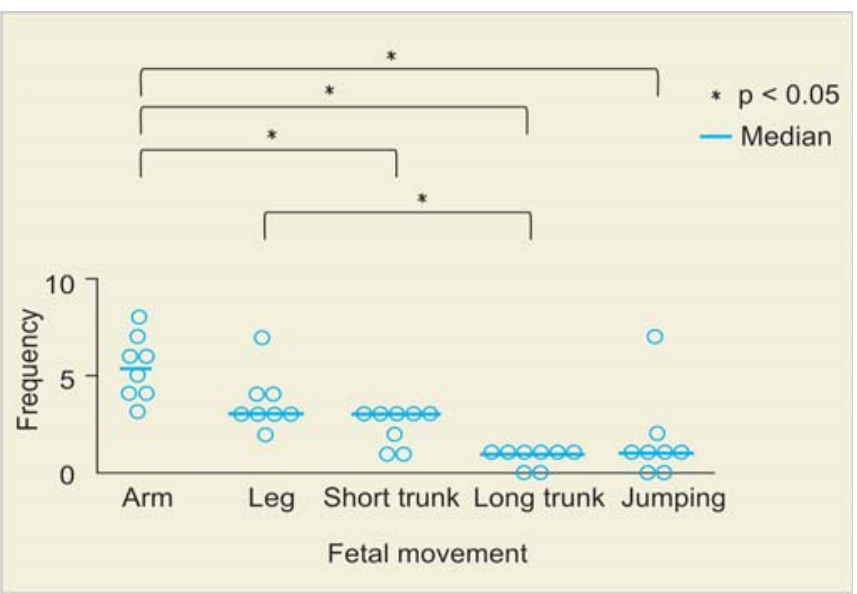

Fig. 3: Frequency of each fetal movement at 10 to 11 weeks of gestation (Courtesy: Reprinted with permission from Hata T et al) ${ }^{36}$

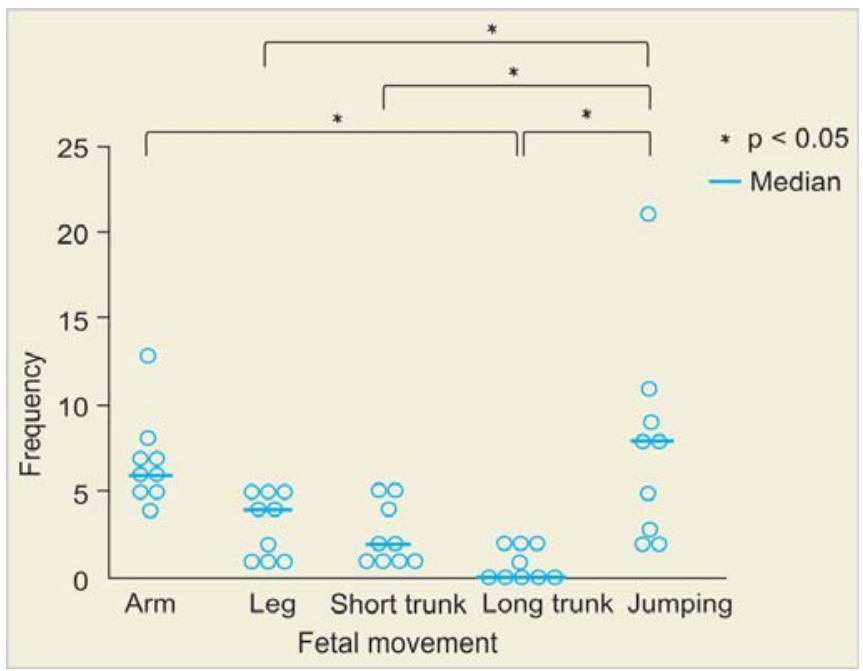

Fig. 4: Frequency of each fetal movement at 12 to 13 weeks of gestation (Courtesy: Reprinted with permission from Hata T et al) ${ }^{36}$

frequency of fetal movement patterns with increasing gestational age. Only the startle movement pattern frequency seemed to remain unchanged during the first trimester. Hata et $\mathrm{al}^{36}$ evaluated the frequencies of five fetal movements (isolated arm and leg, short trunk, long trunk and jumping movements) in 17 normal singleton pregnancies for 10 minutes at 10 to 11 and 12 to 13 weeks of gestation using 4D sonography. Arm movement at 10 to 11 weeks' of gestation was significantly more frequent than short trunk, long trunk and jumping movements (Fig. 3). Leg movement at 10 to 11 weeks of gestation was significantly more frequent than long trunk movement (Fig. 3). Jumping movement at 12 to 13 weeks of gestation was significantly more frequent than leg, short trunk and long trunk movements (Fig. 4). Arm movement at 12 to 13 weeks of gestation was significantly more frequent than long trunk movement (Fig. 4). There was a significant difference in the frequency of jumping movement between 10 to 11 and 


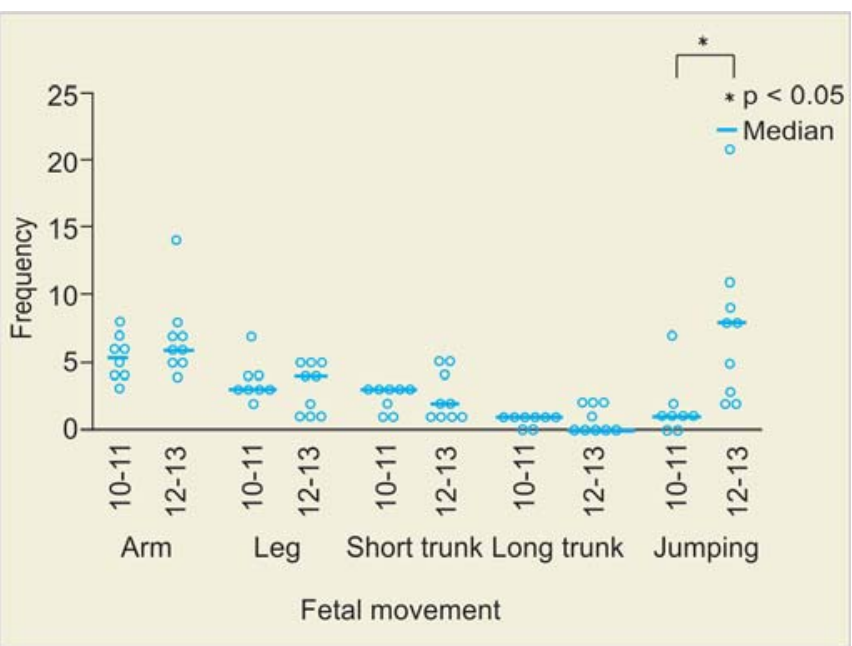

Fig. 5: Comparison of the frequency of each fetal movement between 10 to 11 and 12 to 13 weeks of gestation. (Courtesy: Reprinted with permission from Hata T et al) ${ }^{36}$

12 to 13 weeks of gestation (Fig. 5). However, there were no significant differences in the frequencies of the other four movements between 10 to 11 and 12 to 13 weeks of gestation (Fig. 5). These researchers suggested that the difference in the frequency of the five fetal movements at 10 to 11 and 12 to 13 weeks of gestation might be caused by early neuromuscular development and differentiation of the neuromuscular system. Kurjak et $\mathrm{al}^{37}$ studied a total of 15 fetuses at 13 to 16 weeks of gestation with abdominal 4D sonography for 15 minutes. The amount of isolated arm movement decreased gradually from 13 through 16 weeks. The incidence and pattern of hand to head movement decreased followed by a plateau at 14 weeks of gestation. The incidence of hand to mouth movement reached a plateau at 13 weeks and continued with mild fluctuations until 16 weeks. The incidence of hand to face movement was characterized by a decrease at 14 weeks followed by a plateau. The incidence of hand near face movement was stable between 13 and 16 weeks of gestation with a slight increase at 14 and 15 weeks. The incidence of hand to ear movement showed a rapid trend of decrease between 13 and 16 weeks. These researchers suggested that $4 \mathrm{D}$ sonography is superior to conventional 2D sonography for the qualitative but inferior for the quantitative analysis of fetal hand movements during the early second trimester of pregnancy. Kuno et $\mathrm{al}^{16}$ conducted 4D sonographic examinations involving 11 healthy pregnant women at 14 to 18 weeks of gestation. The most active fetal behavior pattern was arm movement, whereas the least was mouth movement. Each fetal movement was synchronized and harmonized with other movements (a few movement patterns were found to be generated simultaneously). The active phase (time period showing fetal movements) comprised $59.4 \%$ and the resting phase $40.6 \%$ during the period studied.

Only one study evaluated the accuracy of 4D sonography in the assessment of embryonic and early fetal motor activity in comparison with conventional 2D sonography. ${ }^{38}$ 'General body, head and limb movements recorded by 2D sonography were notable by 4D sonography between 6 and 14 weeks of gestation, and there were significant correlations in the frequencies of all observed movement patterns assessed by the two different techniques. However, several movement patterns, such as side-way bending, hiccup, breathing movement, mouth opening and facial movement, could be observed only by the 2D sonographic technique and not by 4D sonography'. In their conclusion, 'both 2D and 4D techniques are required for the assessment of early fetal motor development and motor behavior. It is reasonable to expect that such technological improvement may provide some new information about the fetal motor activity and facilitate the prenatal detection of some neurological disorders'.

\section{LATE SECOND AND THIRD TRIMESTERS}

There have been numerous reports on fetal neurobehavioral assessment using $4 \mathrm{D}$ sonography in the late second and third trimesters of pregnancy. ${ }^{33-35,37,39-41}$ All studies focused on the assessment of fetal facial expressions and movements, and fetal hand to face movements (Figs 6A to 8), because the viewing area was limited to that of the transabdominal probe. Kurjak et al ${ }^{37}$ were the first to use $4 \mathrm{D}$ sonography to study 10 healthy fetuses for 15 minutes at 30 to 33 weeks. Among facial activities observed by 4D sonography, simultaneous eyelid and mouthing movements dominated between 30 and 33 weeks of gestation. Pure mouth movements, such as mouth opening, tongue expulsion, yawning and pouting, were present, but at a significantly lower incidence. Facial expressions, such as smiling and scowling, could be precisely observed using 4D sonography. In another study by this group, 100 women with normal singleton pregnancies were recruited for longitudinal 4D sonographic examinations to evaluate 11 fetal movement and expression parameters from the 15th to 40th weeks. ${ }^{33}$ All types of facial expression were noted as displaying a peak frequency at the end of the second trimester, except for isolated eye blinking, the frequency of which increased at the beginning of the 24th week (Figs 9A to F). A tendency toward decreased frequency of facial expressions and movement patterns with increasing gestational age from second to third trimesters has also been noted. 'This observation appears to be very important, especially since the $2 \mathrm{D}$ technique does not appear capable or comparable to the $4 \mathrm{D}$ technique in terms of evaluating early facial 

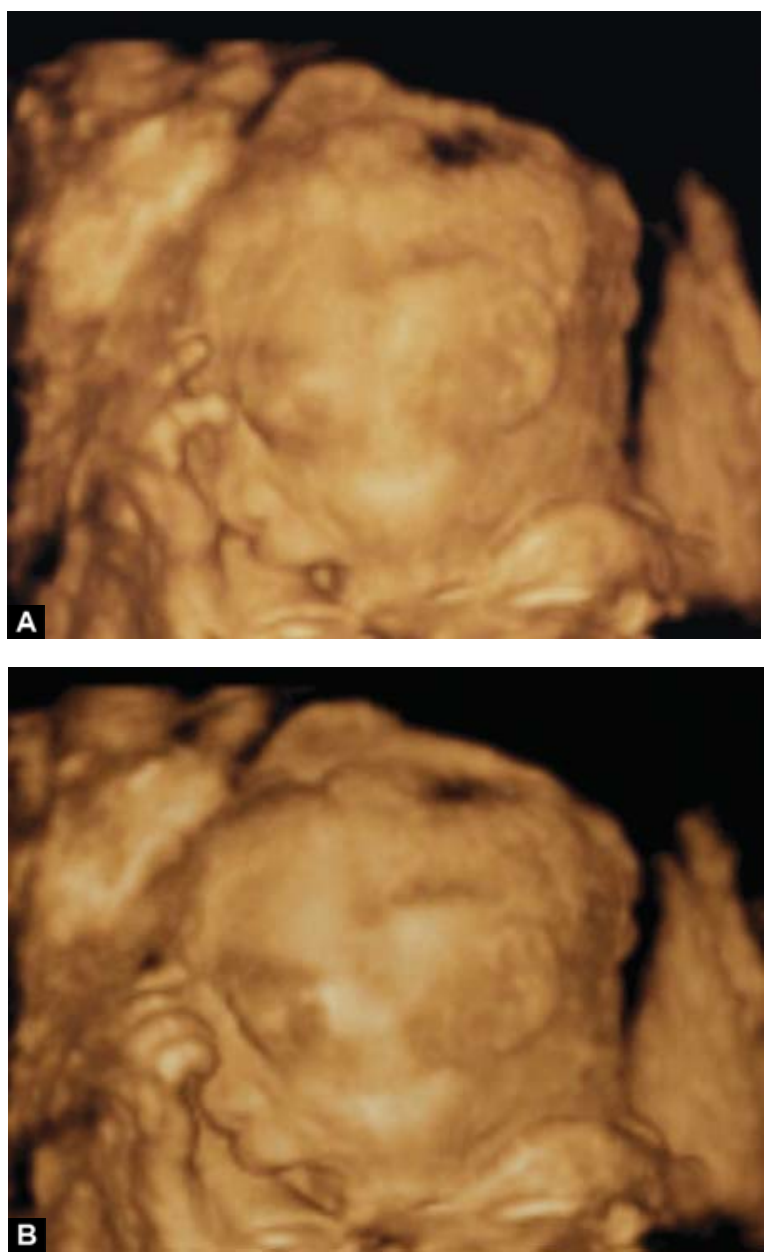

Figs 6 A and B: Consecutive 4D sonographic observation of fetal yawning at 23 weeks and 4 days of gestation

expression. A tendency toward a decreasing frequency of facial expression with increasing gestational age needs to be demonstrated'. ${ }^{17}$ Yigiter and $\mathrm{Kavak}^{35}$ also used 4D sonography to investigate 50 normal fetuses in the second and third trimesters. While mouthing, yawning, tongue expulsion, smiling, sucking and swallowing expressions displayed peak frequencies between the 24th and 32nd gestational weeks, grimacing and eye blinking expressions displayed peak frequencies between the 28th and 36th weeks and after the 32nd weeks respectively. A statistically significant correlation was found between all head movements and hand to body contact patterns during the second and third trimesters, except for head anteflexion. Yan et $\mathrm{al}^{41}$ studied the full range of fetal facial expressions early in the third trimester (from 28 to 34 gestational weeks) using 4D sonographic techniques. Mouthing was the most frequent facial expression, whereas the least frequent were scowling and sucking. Mouthing was evident in all fetuses and significantly more frequent than any other movement. Yawning, smiling and blinking were observed in most cases. Tongue expulsion, scowling and sucking were each

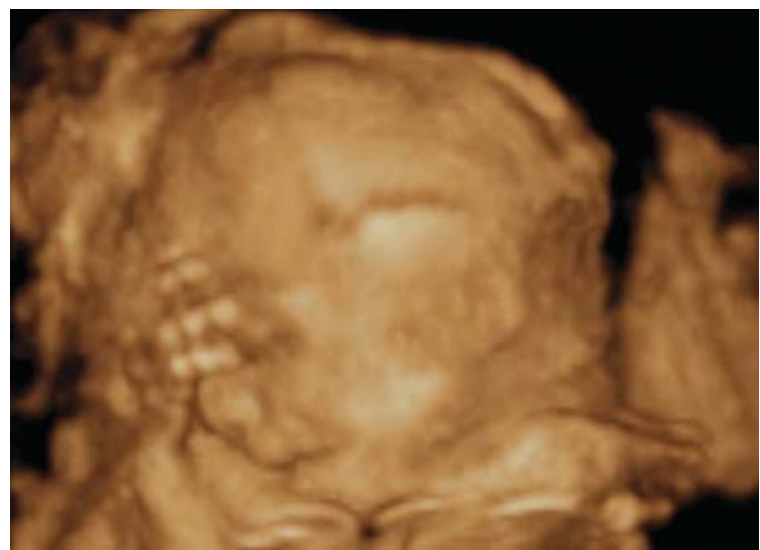

Fig. 7: 4D sonographic observation of an 'embarrassed' pose by a fetus at 23 weeks and 4 days of gestation

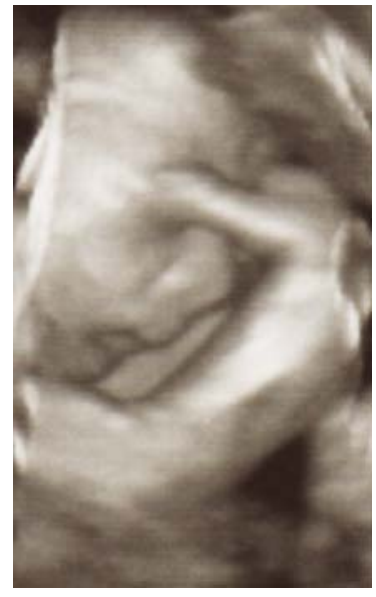

Fig. 8: 4D sonographic observation of an 'embarrassed' pose by a fetus at 30 weeks and 6 days of gestation

observed in about half of the cases studied. A multicentric study was performed in three centers to study 35 fetuses in the first trimester, 28 fetuses in the second trimester and 22 fetuses in the third trimester. ${ }^{34}$ In the second trimester, the number of head and hand movements decreased gradually compared with that in the first trimester. The highest incidence was registered for head retroflexion pattern. Among facial expressions, the highest incidence was found for sucking.

The application of $4 \mathrm{D}$ sonography to the examination of fetal facial movements reveals the existence of a full range of facial expressions similar to emotional expression in adults. ${ }^{18,19,33}$ Moreover, different facial expressions and movements depicted by 4D sonography might represent fetal awareness. ${ }^{40}$ 'The question raised here is whether or not facial expressions represent a reliable behavior or emotional state or constitute reflexive behavior on the part of the fetus'. ${ }^{33}$ The answer to this question is currently unknown. However, we would like to believe that fetal facial expressions and movements are a reliable behavior or emotional state of the fetus in utero. Further development 

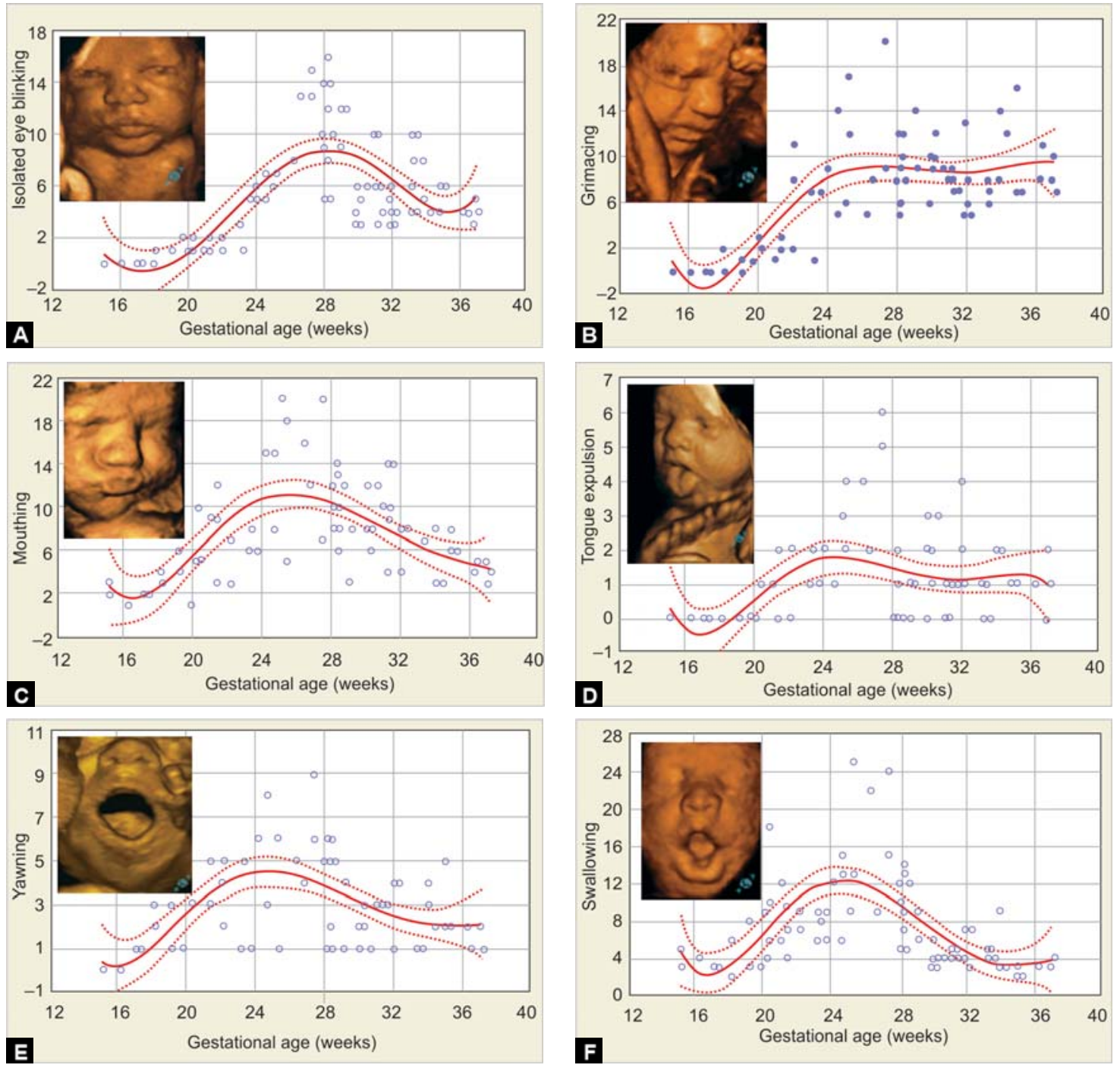

Figs 9A to F: Frequency of observed facial expressions vs gestational age (Courtesy: Reprinted with permission from Kurjak A et al) ${ }^{4}$

of the technology will allow better recognition of fetal emotion and awareness in utero.

Andonotopo and Kurjak ${ }^{39}$ compared the frequency of all types of fetal facial expression between 50 normal and 50 growth-restricted fetuses in the third trimester. They noted a tendency for growth-restricted fetuses to have less behavioral activity than normal fetuses in all observed movement patterns. In the normal fetus, movements were complex and variable in composition, speed and intensity, but a poor repertoire of movement patterns was observed in 11 out of 50 growth-restricted fetuses. The movements were monotonous with a lack of complexity of the sequence of successive movement components. Although parameters, such as amplitude and speed were reduced, it must be emphasized that the overall monotony and predominantly small range of amplitude were the most notable features. Movements of the head and hand, varying in amplitude, speed and intensity, were seen only in the normal fetuses and were performed slowly with small amplitude in growthrestricted fetuses. Position changes, such as rotations around the longitudinal axis, were seen more often in normal fetuses than in growth-restricted fetuses. They encouraged the future use of $4 \mathrm{D}$ sonography for the quantitative and qualitative assessment of fetal behavior as possible indicators of the neurological condition in growth-restricted fetuses.

In anencephalic fetuses, almost an absence of movements in the lower extremities was observed. ${ }^{4,25,26}$ General movements in the first trimester showed a lack of positional changes, high volume and hypertonia with reduced participating body parts. No facial expressions during the second and third trimesters were noted. All the frequencies of movement patterns were decreased compared with normal longitudinal parameters in all trimesters.

'There have been no studies on the comparison of 2D and $4 \mathrm{D}$ techniques to assess fetal facial expression or behavior in the late second and third trimesters of pregnancy, 
in which the neurobehavioral regulations of fetal movement are the most important'. ${ }^{17}$

\section{INTERTWIN CONTACT AND INTRAPAIR STIMULATION}

There have been only five studies to investigate intertwin contact and intrapair stimulation in twin pregnancies using conventional 2D sonography during pregnancy. ${ }^{30,31,42-44}$ 'However, 2D sonography requires frequent changes of the transducer to visualize both twins simultaneously; even then, complex contacts are not always fully demonstrated, and fetal movements outside the scanning plane cannot be displayed on the monitor because of the $2 \mathrm{D}$ character of real-time scanning'. ${ }^{17}$

Sasaki et $\mathrm{al}^{45}$ were the first to evaluate the total number of intertwin contact between monochorionic diamniotic (MD) and dichorionic diamniotic (DD) twins using 4D sonography late in the first trimester of pregnancy. Six MD and eight DD pregnancies were studied for 30 minutes with 4D sonography at 10 to 11 and 12 to 13 weeks of gestation, and a total of 10 intertwin contacts (head to head, head to arm, head to trunk, head to leg, arm to arm, arm to trunk, arm to leg, trunk to trunk, trunk to leg and leg to leg contact) were evaluated. There was a significant difference in the total number of all contacts between MD and DD twins at 10 to 11 weeks of gestation ${ }^{17}$ (Fig. 10). However, no significant difference in the total number of all contacts was found between MD and DD twins at 12 to 13 weeks of gestation $^{17}$ (Fig. 11). There was a significant difference in the total number of all contacts between 10 to 11 and 12 to 13 weeks of gestation in DD twins ${ }^{17}$ (Fig. 12). However, no significant difference in the total number of all contacts was noted between 10 to 11 and 12 to 13 weeks of gestation in $\mathrm{MD}$ twins ${ }^{17}$ (Fig. 13). There were no significant differences in the frequencies of 10 types of contact at 10 to 11 or 12 to 13 weeks of gestation in MD pregnancies (Figs 14 and 15). There were also no significant differences in the frequencies of 10 types of contact at 10 to 11 or 12 to 13 weeks of gestation in DD pregnancies (Figs 16 and 17). There was a significant difference in the frequency of head to arm contact between MD and DD twins at 12 to 13 weeks gestation. ${ }^{46}$ There were also significant differences in head to arm, head to trunk, arm to arm and arm to trunk contact between 10 to 11 and 12 to 13 weeks of gestation in MD twins. ${ }^{46}$ However, there was no significant difference in the frequency of other types of contact between MD and DD pregnancies at 12 to 13 weeks of gestation, and between 10 to 11 and 12 to 13 weeks in MD twins. The frequencies of no reaction (twins appear to touch each other but there is no clear reaction) and reaction (twins appear to touch each other and there is a clear reaction by the co-twin) movements

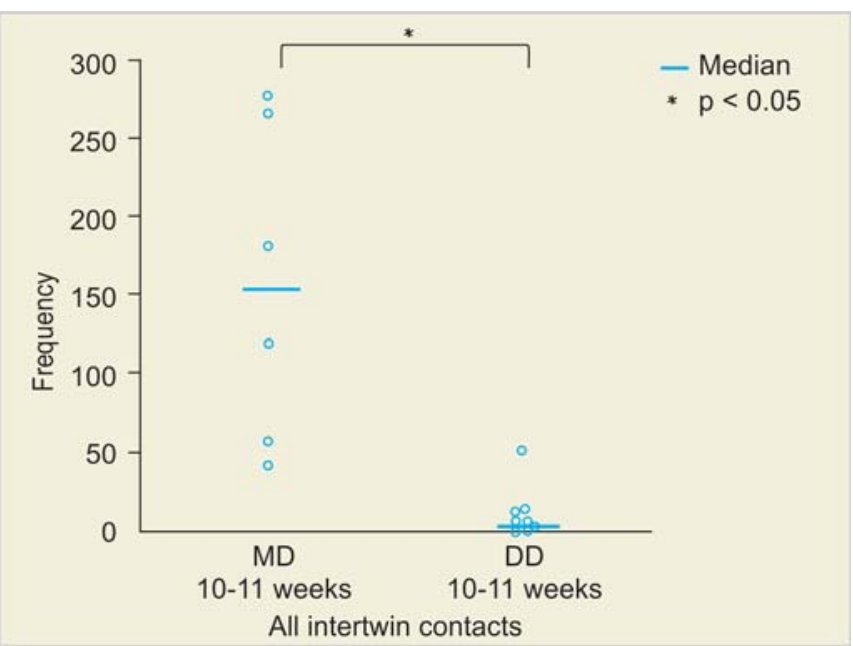

Fig. 10: Total frequencies of all intertwin contacts between MD and DD twins at 10 to 11 weeks (Courtesy: Reprinted with permission from Hata $\mathrm{T}$ et al $)^{17}$

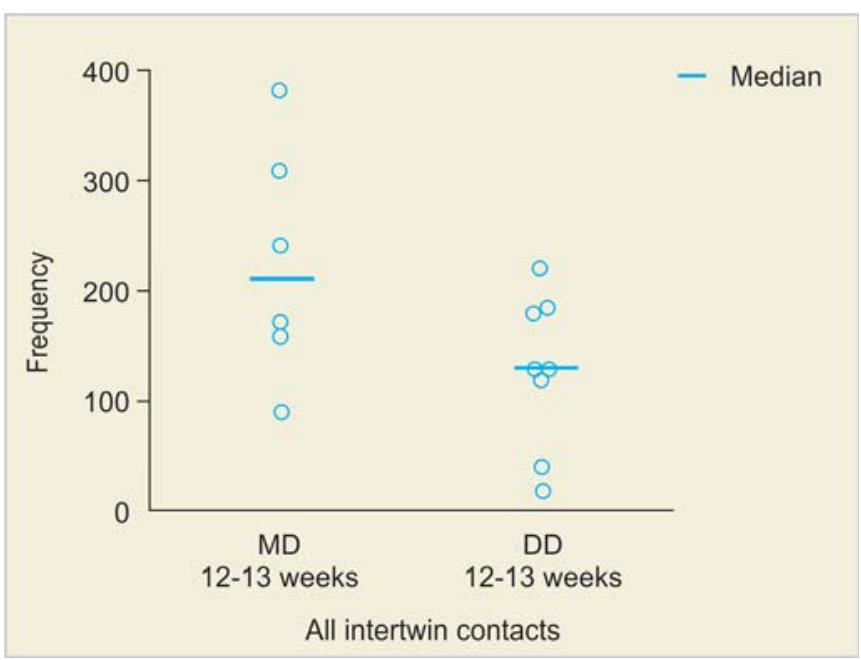

Fig. 11: Total frequencies of all intertwin contacts between MD and DD twins at 12 to 13 weeks (Courtesy: Reprinted with permission from Hata $\mathrm{T}$ et al) ${ }^{17}$

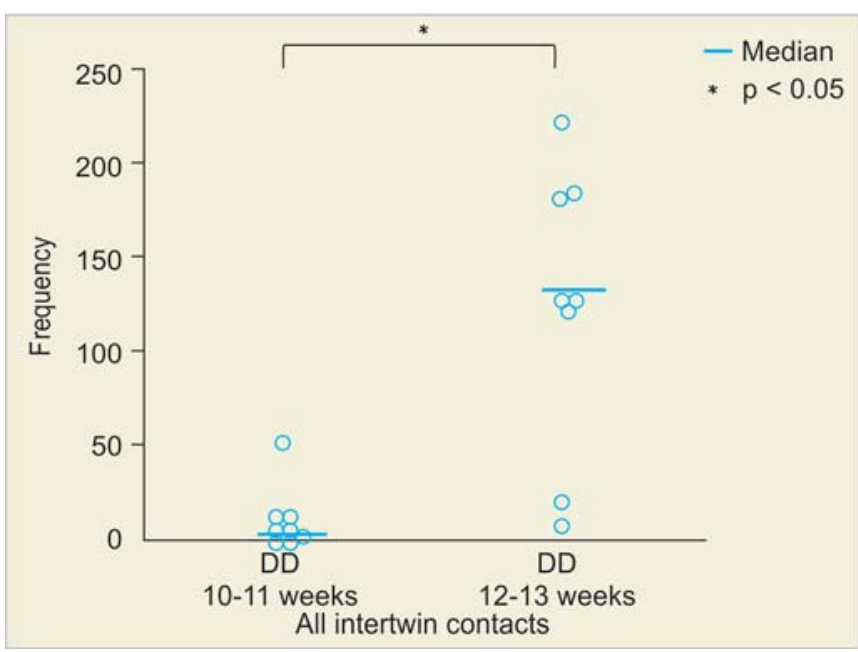

Fig. 12: Total frequencies of all intertwin contacts between 10 to 11 and 12 to 13 weeks in DD twins (Courtesy: Reprinted with permission from Hata T et al) $)^{17}$ 


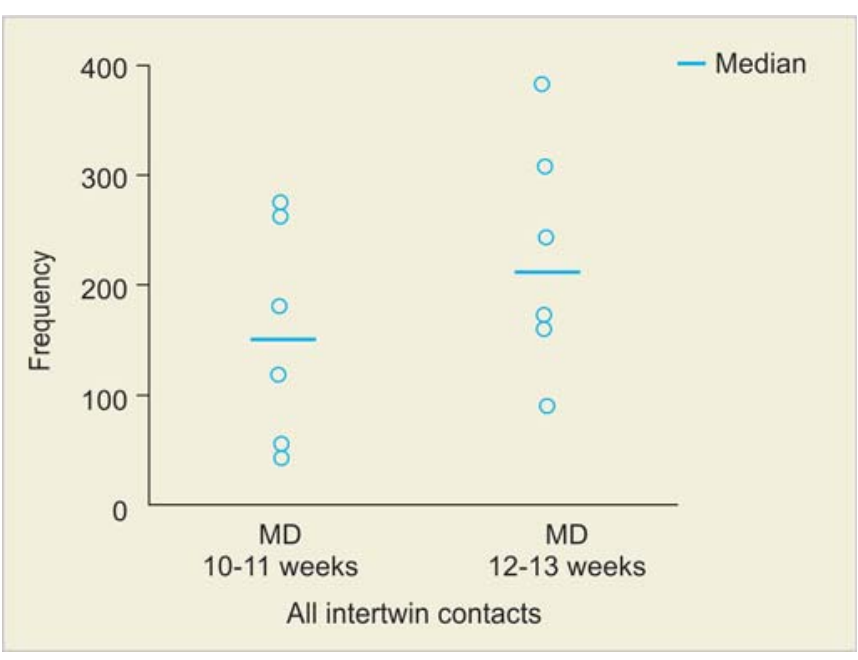

Fig. 13: Total frequencies of all intertwin contacts between 10 to 11 and 12 to 13 weeks in MD twins (Courtesy: Reprinted with permission from Hata $\mathrm{T}$ et al) ${ }^{17}$

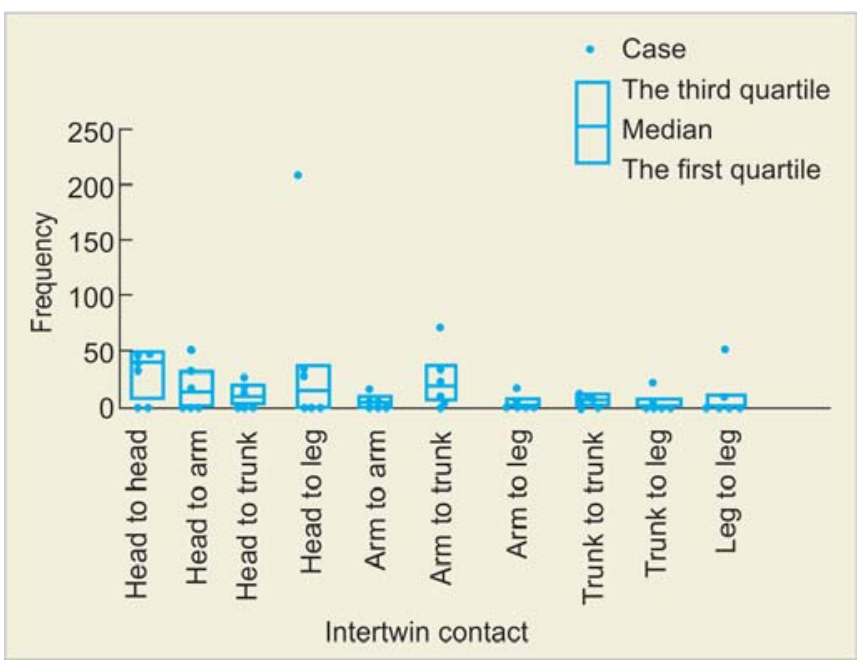

Fig. 14: Frequencies of 10 types of contact at 10 to 11 weeks of gestation in MD pregnancies

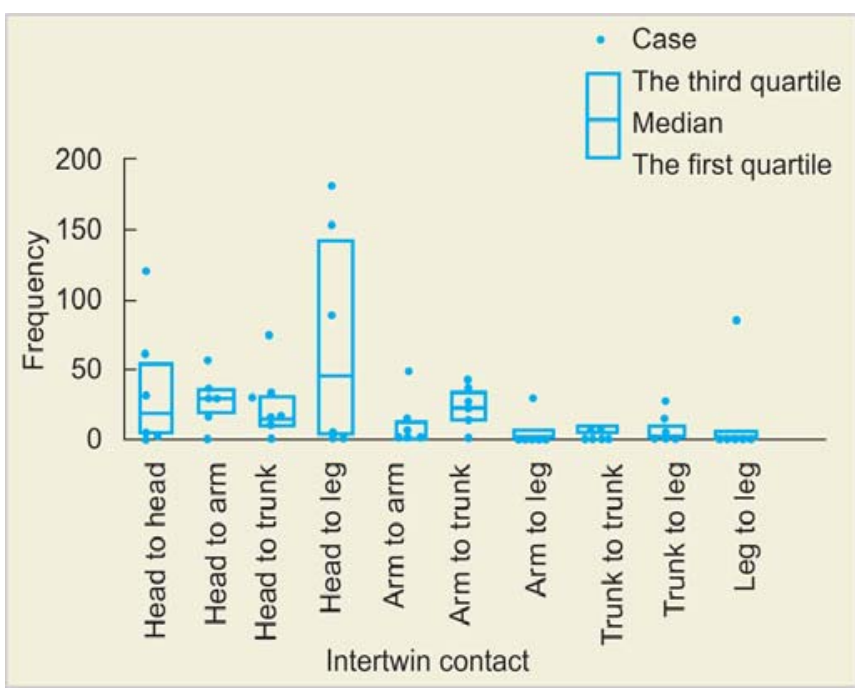

Fig. 15: Frequencies of 10 types of contact at 12 to 13 weeks of gestation in MD pregnancies

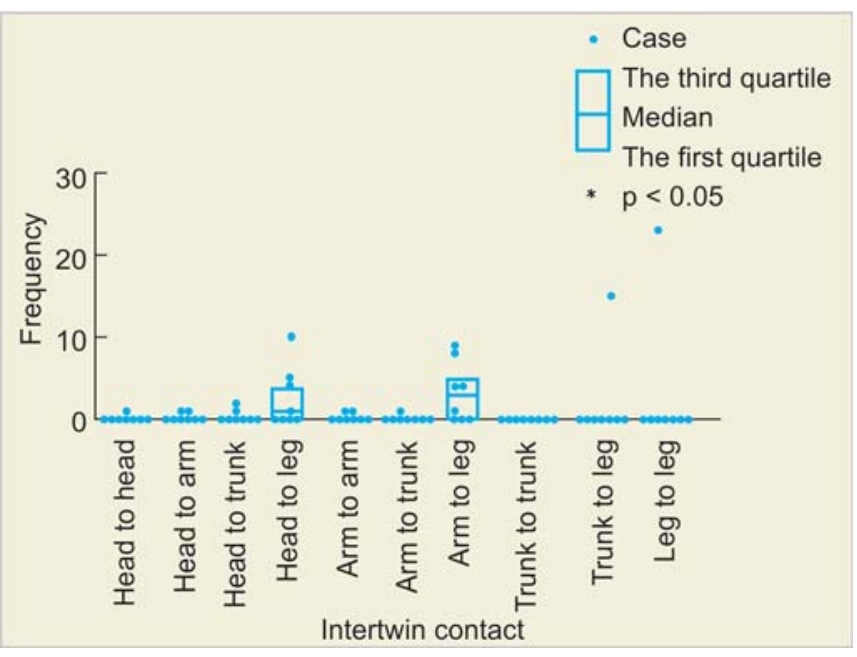

Fig. 16: Frequencies of 10 types of contact at 10 to 11 weeks of gestation in DD pregnancies

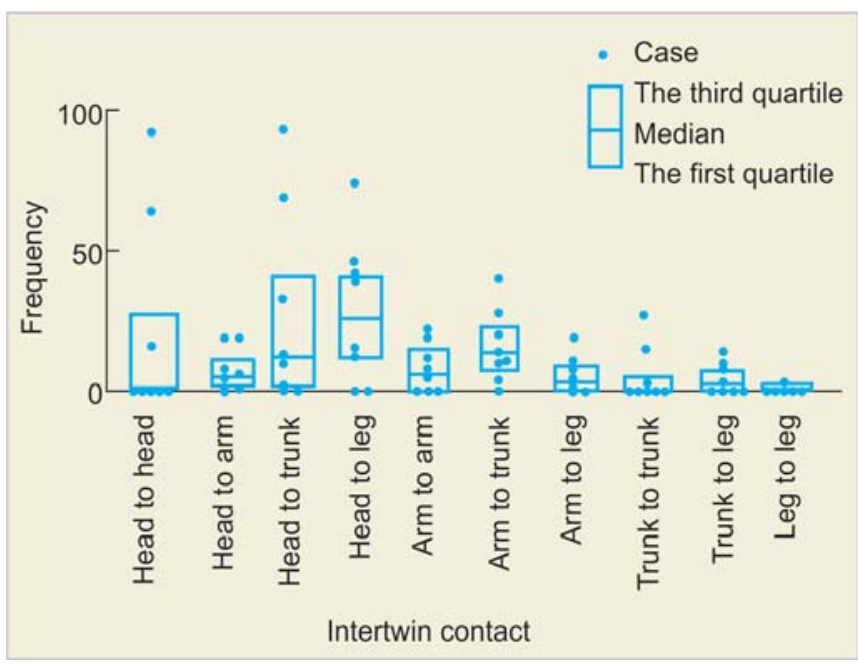

Fig. 17: Frequencies of 10 types of contact at 12 to 13 weeks of gestation in DD pregnancies

were evaluated at 12 to 13 weeks of gestation ${ }^{47}$ (Figs 18A to $\mathrm{C}$ and $19 \mathrm{~A}$ and $\mathrm{B}$ ). There was no significant difference in the rate of reaction movements between MD (median, 33.6\%) and DD (median, 33.9\%) twins (Fig. 20). The median rate of reaction movements in all 14 twins was $33.9 \%$ (Fig. 20). These researchers suggested that the incidence of reflex movement of the co-twin on being touched by the other twin late in the first trimester is greater than that assessed by conventional 2D sonography.

Degani et $\mathrm{al}^{48}$ studied intertwin differences in activity during early pregnancy and examined their relationship to subsequent infant twins temperament. Measures of fetal motor activity (frequency, duration and number of movements) were made on 26 twin pairs for 10 minutes in the late first and early second trimesters (11 to 14 weeks of gestation) using 4D sonography. After birth, maternal 

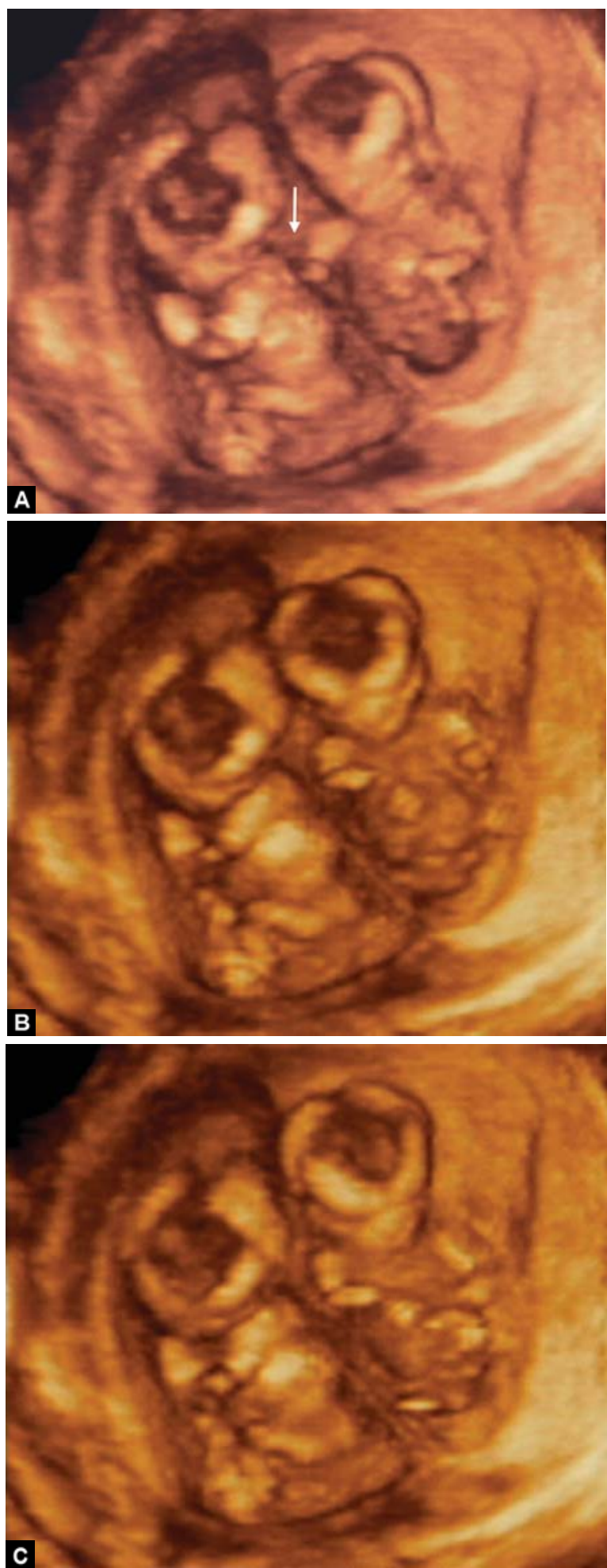

Figs 18A to C: $4 \mathrm{D}$ sonographic observations of a DD twin fetus at 13 weeks and 2 days of gestation $(A \rightarrow C)$. Arm to trunk contact (arrow) is noted (A). However, there is no clear reaction of the cotwin fetus $(\mathrm{B} \rightarrow \mathrm{C})$ (Courtesy: Reprinted with permission from Hata T et al $)^{47}$

reports on infants of temperament using infant behavior questionnaire (IBQ) and revised $\mathrm{IBQ}^{49,50}$ at 3 and 6 months of age were obtained. The more active twin in each pair showed a close correlation with prenatal intertwin differences in activity. These authors suggested that differences in activity in each pregnancy even before the
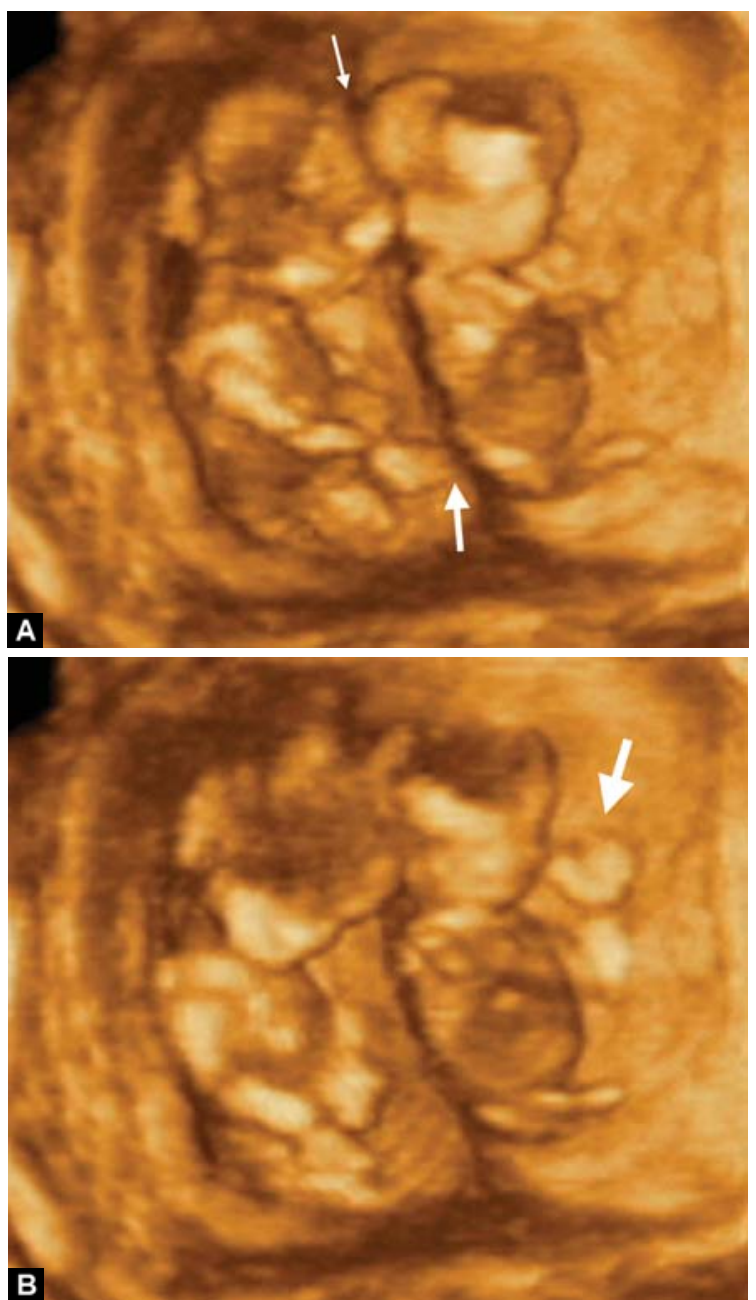

Figs 19A and B: 4D sonographic observations of a DD twin fetus at 13 weeks and 2 days of gestation $(A \rightarrow B)$. Head to head (smal arrow) and leg to trunk (medium arrow) contacts are noted simultaneously (A). There is a clear reaction of the cotwin fetus, who raises his left hand (large arrow) (B) (Courtesy: Reprinted with permission from Hata T et al $)^{47}$

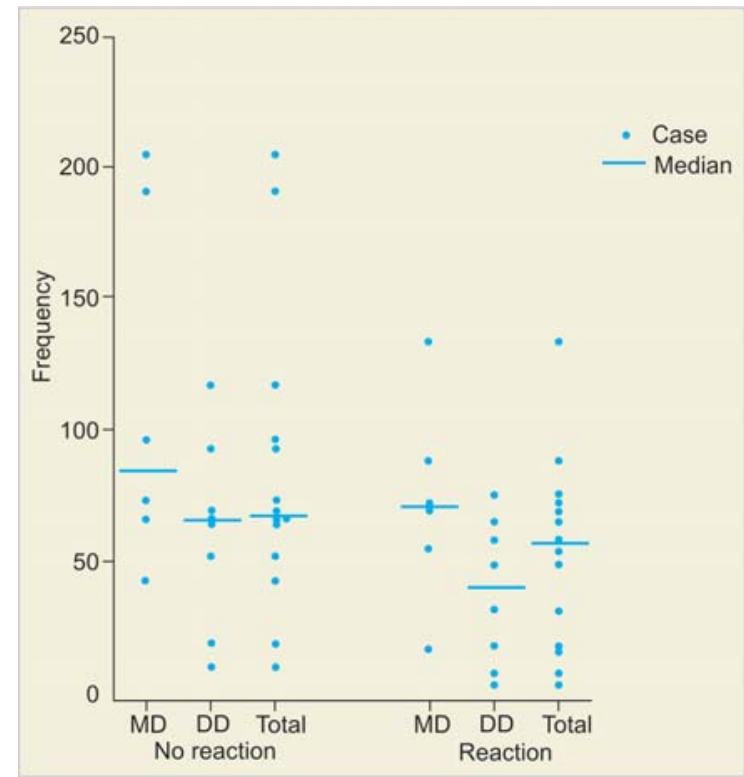

Fig. 20: Comparison of the frequency of no reaction and reaction movements in six MD, eight DD, and total twins at 12 to 13 weeks of gestation (Courtesy: Reprinted with permission from Hata T et al) ${ }^{47}$ 


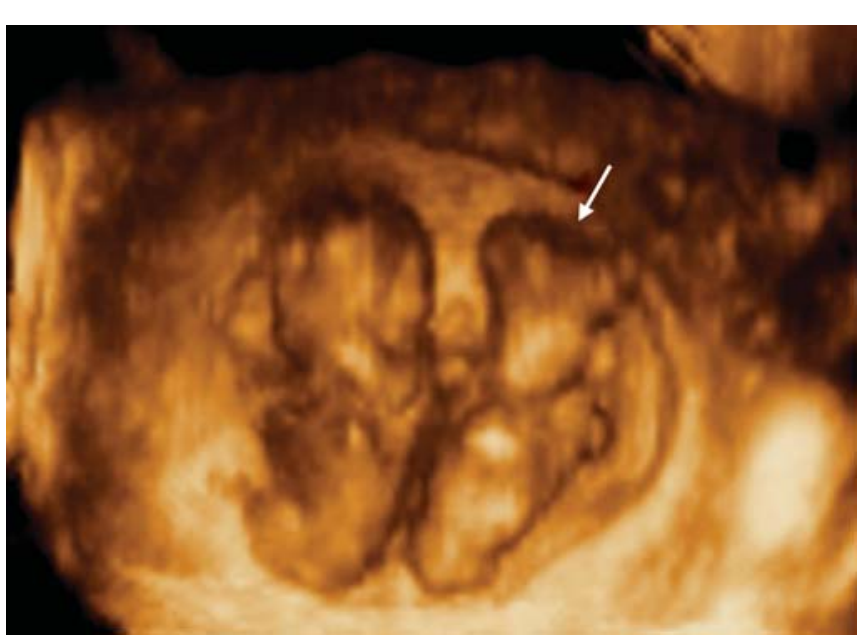

Fig. 21: 3D/4D ultrasound imaging of a MD twin pregnancy with acrania of one fetus (arrow) at 11 weeks and 4 days of pregnancy (Courtesy: Reprinted with permission from Hata T et al) ${ }^{51}$

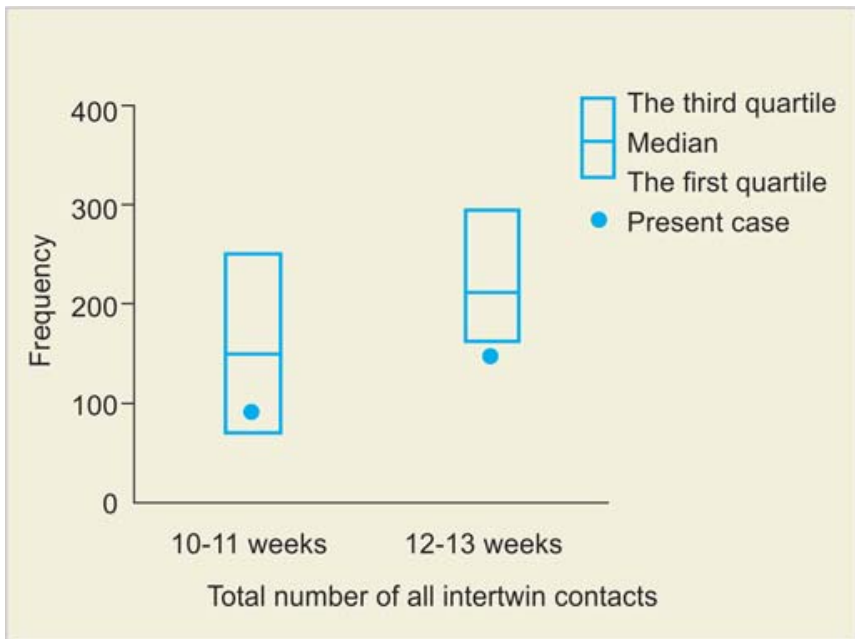

Fig. 22: Total number of all intertwin contacts in the present case $(\bullet)$. The quartile ranges at 10 to 11 and 12 to 13 weeks were adopted from normal MD twins in our previous investigation ${ }^{45}$ (Courtesy: Reprinted with permission from Hata T et al) ${ }^{51}$

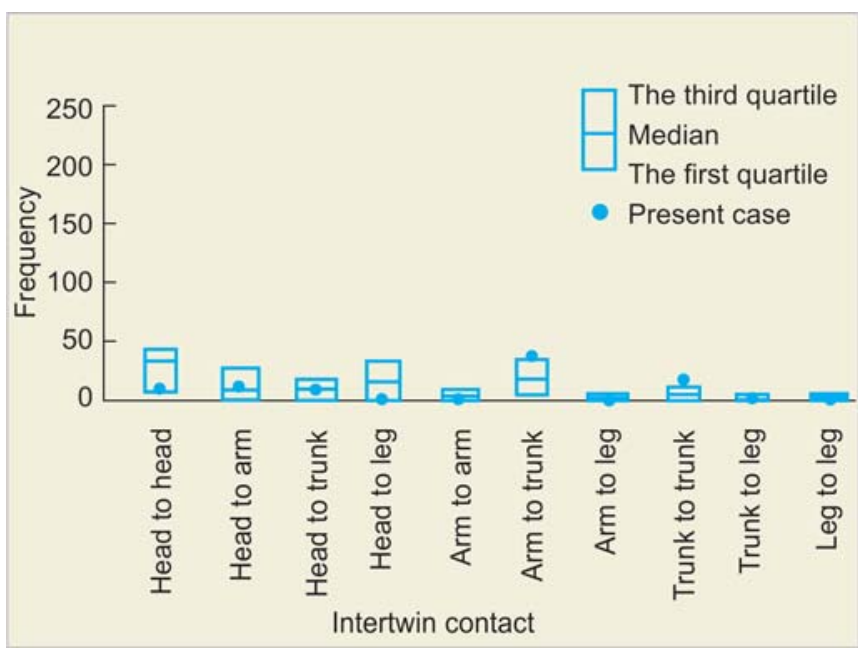

Fig. 23: Frequencies of 10 types of intertwin contact in the present case $(\bullet)$ at 10 to 11 weeks. The quartile ranges at 10 to 11 weeks were adopted from normal MD twins in our previous investigation ${ }^{46}$ (Courtesy: Reprinted with permission from Hata T, et al) ${ }^{51}$

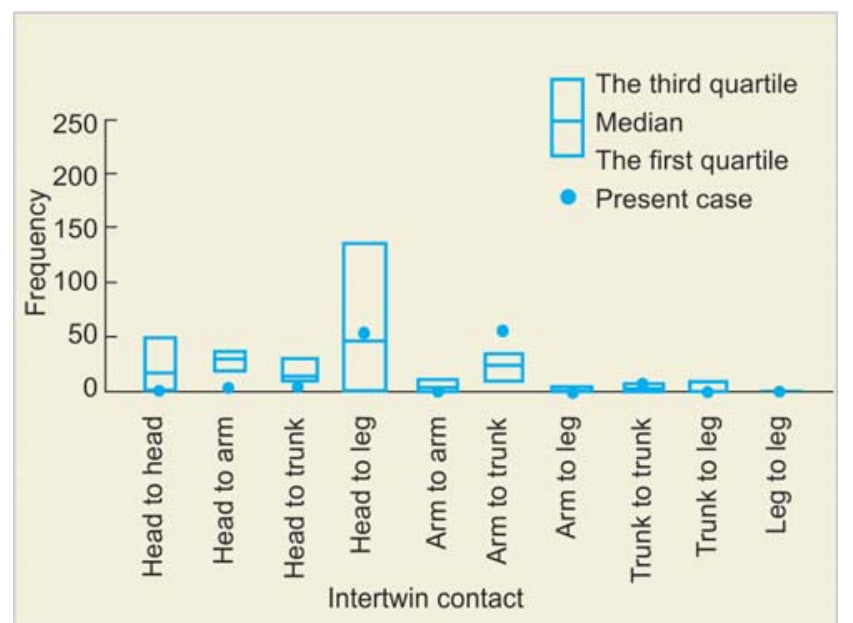

Fig. 24: Frequencies of 10 types of intertwin contact in the present case (•) at 12 to 13 weeks. The quartile ranges at 12 to 13 weeks were adopted from normal monochorionic diamniotic (MD) twins in our previous investigation ${ }^{46}$ (Courtesy: Reprinted with permission from Hata T et al) ${ }^{51}$

emergence of fetal behavioral patterns were followed by differences in temperament postnatally.

Hata et $\mathrm{al}^{51}$ were the first to report on $4 \mathrm{D}$ sonographic assessment of intertwin contact in a case of MD twin with an acrania of one twin fetus late in the first trimester (Fig. 21). The total number of intertwin contacts in this patient was low compared with those of normal MD twin fetuses $^{46}$ at 10 to 11 and 12 to 13 weeks of gestation (Fig. 22). The frequencies of 10 types of intertwin contact at 10 to 11 weeks were almost within quartile ranges (Fig. 23), but the frequencies of about half of contacts at 12 to 13 weeks were low (Fig. 24). These researchers suggested that the decreased number of intertwin contacts in the late first trimester might be due to decreased frequencies of some movement patterns in the anencephalic fetus.

\section{CONCLUSION}

This review focused on 4D sonographic studies evaluating fetal neurobehavior, intertwin contact and intrapair stimulation in twin pregnancies. '4D sonographic studies of fetal behavior, behavior-related phenomena and fetal reflexes may provide us with a great possibility of understanding the hidden function of the development pathway of the fetal brain and central nervous system and the potentialities of originating a neurological investigation in utero' ${ }^{4}$ There are fetal behaviors that can be detected by the $4 \mathrm{D}$ sonographic assessment procedure in instances, where the 2D technique cannot provide the same information. One aspect that appears to favor the 4D technique is in the evaluation of facial movement and expression. 4D sonography should be an important modality in future fetal behavioral research and in the evaluation of 
fetal well-being. If we can observe fetal behavior precisely using this technique, we can obtain new and/or additional information to facilitate improved diagnosis and understanding of fetal brain impairment in utero. Moreover, we might uncover new fetal behavioral functions and interhuman relationships'. ${ }^{28}$ 'The study of fetal behavior has important benefit for fetal health and the long-term future of the child and marks the next major step forward in the evaluation of fetal health, the determination of fetal brain function'. ${ }^{1}$ Further studies involving a larger sample size are needed to ascertain and extend the present and future applications of this modality to fetal neurobehavioral assessment.

\section{REFERENCES}

1. Hepper PG. Fetal behavior: Why so skeptical? Ultrasound Obstet Gynecol 1996;8:145-48.

2. Prechtl HF. State of the art of a new functional assessment of the young nervous system: An early predictor of cerebral palsy. Early Hum Dev 1997;50:1-11.

3. Nijhuis JG. Fetal behavior. Neurobiol Aging 2003;24(Suppl 1):S41-46.

4. Kurjak A, Lausin I, Azumendi G. Assessment of fetal behaviour by $3 \mathrm{D}$ and 4D sonography. In: Hata T, Kurjak A, Kozuma S (Eds): Current Topics on Fetal 3D/4D Ultrasound Bentham Science Publishers 2009;209-41. (www.bentham.org/ebooks/ 9781608050192/index.htm)

5. Shawker TH, Schuette WH, Whitehouse W, Rifka SM. Early fetal movement: A real-time ultrasound study. Obstet Gynecol 1980;55:194-98.

6. de Vries JIP, Visser GHA, Prechtl HFR. The emergence of fetal behaviour (I). Qualitative aspect. Early Hum Dev 1982;7: 301-22.

7. de Vries JIP, Visser GHA, Prechtl HFR. The emergence of fetal behaviour (II). Quantitative aspects. Early Hum Dev 1985;12: 99-120.

8. Bekedam DJ, Visser GH, de Vries JIP, Prechtl HFR. Motor behavior in the growth retarded fetus. Early Hum Dev 1985;12:155-65.

9. Visser GHA, Laurini RN, de Vries JIP, Bekedam DJ, Prechtl HFR. Abnormal motor behaviour in anencephalic fetuses. Early Hum Dev 1985;12:173-82.

10. de Vries JIP, Visser GHA, Prechtl HFR. The emergence of fetal behaviour. III. Individual differences and consistencies. Early Hum Dev 1988;16:85-103.

11. Jorgensen NP, Marsal, K, Lindstrom K. Quantification of fetal motor activity in early pregnancy. Eur J Obstet Gynecol Reprod Biol 1989;30:11-18.

12. Sival DA. Studies on fetal motor behavior in normal and complicated pregnancies. Early Hum Dev 1993;34:13-20.

13. Joseph R. Fetal brain behavior and congnitive development. Dev Rev 2000;20:81-98.

14. de Vries JIP, Fong BF. Normal fetal motility: An overview. Ultrasound Obstet Gynecol 2006;27:701-11.

15. de Vries JIP, Fong BF. Changes in fetal motility as a result of congnitive disorders: An overview. Ultrasound Obstet Gynecol 2007;29:590-99.
16. Kuno A, Akiyama M, Yamashiro C, Tanaka H, Yanagihara T, Hata T. Three-dimensional sonographic assessment of fetal behavior in the early second trimester of pregnancy. J Ultrasound Med 2001;20:1271-75.

17. Hata T, Kanenishi K, Tanaka H, Marumo G, Sasaki M. Fourdimensional ultrasound evaluation of fetal neurobehavioral development. Donald School J Ultrasound Obstet Gynecol 2010;4:233-48.

18. Azumendi G, Kurjak A. Three-dimensional and fourdimensional sonography in the study of the fetal face. Ultrasound Rev Obstet Gynecol 2003;3:160-69.

19. Andonotopo W, Stanojevic M, Kurjak A, Azumendi G, Carrera JM. Assessment of fetal behavior and general movements by four-dimensional sonography. Ultrasound Rev Obstet Gynecol 2004;4:103-14.

20. Pooh RK, Ogura T. Normal and abnormal fetal hand positioning and movement in early pregnancy detected by three- and fourdimensional ultrasound. Ultrasound Rev Obstet Gynecol 2004;4:46-51.

21. Salihagic-Kadic A, Kurjak A, Medic M, Andonotopo W, Azumendi G. New data about embryonic and fetal neurodevelopment and behavior obtained by 3D and 4D sonography. J Perinat Med 2005;33:478-90.

22. Kurjak A, Carrera JM, Medic M, Azumendi G, Andonotopo W, Stanojevic M. The antenatal development of fetal behavioral patterns assessed by four-dimensional sonography. J Matern Fetal Neonatal Med 2005;17:401-16.

23. Kurjak A, Pooh RK, Merce LT, Carrera JM, Salihagic-Kadic A, Andonotopo W. Structural and functional early human development assessed by three-dimensional and fourdimensional sonography. Fertil Steril 2005;84:1285-99.

24. Walusinski O, Kurjak A, Andonotopo W, Azumendi G. Fetal yawning assessed by 3D and 4D sonography. Ultrasound Rev Obstet Gynecol 205;5:210-17.

25. Ahmed B, Kurjak A, Andonotopo W, Khenyab N, Saleh N, AlMansoori Z. Fetal behavioral and structural abnormalities in high risk fetuses assessed by 4D sonography. Ultrasound Rev Obstet Gynecol 2005;5:275-87.

26. Andonotopo W, Kurjak A, Kosuta MI. Behavior of an anencephalic fetus studied by 4D sonography. J Matern Fetal Neonatal Med 2005;17:165-68.

27. Kurjak A, Azumendi G, Andonotopo W, Salihagic-Kadic A. Three- and four-dimensional ultrasonography for the structural and functional evaluation of the fetal face. Am J Obstet Gynecol 2007;196:16-28.

28. Hata T, Dai SY, Marumo G. Ultrasound for evaluation of fetal neurobehavioural development: From 2D to 4D ultrasound. Inf Child Dev 2010;19:99-118.

29. Campbell S. 4D, or not 4D: That is the question. Ultrasound Obstet Gynecol 2002;19:1-4.

30. Arabin B, Bos R, Rijlaarsdam R, Mohnhaupt A, van Eyck J. The onset of inter-human contacts: Longitudinal ultrasound observations in early twin pregnancies. Ultrasound Obstet Gynecol 1996;8:166-73.

31. Piontelli A, Bocconi L, Kustermann A, Tassis B, Zoppini C, Nicolini U. Patterns of evoked behaviour in twin pregnancies during the first 22 weeks of gestation. Early Hum Dev 1997;50:39-45

32. Kurjak A, Vecek N, Hafner T, Bozek T, Kurjak BF, Ujevic B. Prenatal diagnosis: What does four-dimensional ultrasound add? J Perinat Med 2002;30:57-62. 
33. Kurjak A, Andonotopo W, Hafner T, Salihagic-Kadic A, Stanojevic M, Azumendi G, et al. Normal standards for fetal neurobehavioral developments-longitudinal quantification by four-dimensional sonography. J Perinat Med 2006;34:56-65.

34. Kurjak A, Stanojevic M, Andonotopo W, Scazzocchio-Duenas E, Azumendi G, Carrera JM. Fetal behavior assessed in all three trimesters of normal pregnancy by four-dimensional ultrasonography. Croat Med J 2005;46:772-80.

35. Yigiter AB, Kavak ZN. Normal standards of fetal behavior assessed by four-dimensional sonography. J Matern Fetal Neonatal Med 2006;19:707-21.

36. Hata T, Kanenishi K, Sasaki M. Four-dimensional sonographic assessment of fetal movement in the late first trimester. Int $\mathrm{J}$ Gynecol Obstet 2010;109:190-93.

37. Kurjak A, Azumendi G, Vecek N, Kupesic S, Solak M, Varga $\mathrm{D}$, et al. Fetal and movements and facial expression in normal pregnancy studied by four-dimensional sonography. J Perinat Med 2003;31:496-508.

38. Andonotopo W, Medic M, Salihagic-Kadic A, Milenkovic D, Maiz N, Scazzocchio E. The assessment of fetal behavior in early pregnancy: Comparison between 2D and 4D sonographic scanning. J Perinat Med 2005;33:406-14.

39. Andonotopo W, Kurjak A. The assessment of fetal behavior of growth restricted fetuses by 4D sonography. J Perinat Med 2006;34:471-78.

40. Kurjak A, Stanojevic M, Azumendi G, Carrera JM. The potential of four-dimensional (4D) ultrasonography in the assessment of fetal awareness. J Perinat Med 2005;33:46-53.

41. Yan F, Dai SY, Akther N, Kuno A, Yanagihara T, Hata T. Fourdimensional sonographic assessment of fetal facial expression ealy in the third trimester. Int J Gynecol Obstet 2006;94: 108-13.

42. Sadovsky E, Ohel G, Simon A. Ultrasonographical evaluation of the incidence of simultaneous and independent movements in twin fetuses. Gynecol Obstet Invest 1987;23:5-9.

43. Zimmer EZ, Goldstein I, Alglay S. Simultaneous recording of fetal breathing movements and body movements in twin pregnancy. J Perinat Med 1988;16:109-12.

44. Samueloff A, Younis JS, Strauss N, Baras M, Sadovsky E. Incidence of spontaneous and evoked fetal movements in the first half of twin pregnancy. Gynecol Obstet Invest 1991;31; 200-03.

45. Sasaki M, Yanagihara T, Naitoh N, Hata T. Four-dimensional sonographic assessment of inter-twin contact late in the first trimester. Int J Gynecol Obstet 2010;108:104-07.

46. Hata T, Sasaki M, Yanagihara T. Difference in the frequency of types of inter-twin contact at 10-13 weeks' gestation: Preliminary four-dimensional sonographic study. J Matern Fetal Neonatal
Med 2011. Early Online, 1-5. DOI: 10.3109/14767058.2011. 568551.

47. Hata T, Kanenishi K, Sasaki M, Yanagihara T. Fetal reflex movement in twin pregnancies late in the first trimester: 4D sonographic study. Ultrasound Med Biol 2011;37:1948-51.

48. Degani S, Leibovitz Z, Shapiro I, Ohel G. Twins' temperament: Early prenatal sonographic assessment and postnatal correlation. J Perinatol 2009;29:337-42.

49. Rothbart MK. Longitudinal observation of infant temperament. Dev Psychol 1986;22:356-65.

50. Gartstein MA, Rothbart MK. Studying infant temperament via the revised infant behavior questionnaire. Infant Beh Dev 2003;26:64-86.

51. Hata T, Kanenishi K, Hanaoka U, Sasaki M, Yanagihara T. Inter-twin contact in a case of monochorionic diamniotic twins with acrania of one twin fetus at 10-13 weeks' gestation. J Med Ultrasonics 2012;39:45-47.

\section{ABOUT THE AUTHORS}

\section{Toshiyuki Hata}

Professor and Chairman, Department of Perinatology and Gynecology Kagawa University School of Medicine, Kagawa, Japan

\section{Miki Sato}

Assistant Professor, Department of Perinatology and Gynecology Kagawa University School of Medicine, Kagawa, Japan

\section{Kenji Kanenishi}

Lecturer, Department of Perinatology and Gynecology, Kagawa University School of Medicine, Kagawa, Japan

\section{Uiko Hanaoka}

Assistant Professor, Department of Perinatology and Gynecology Kagawa University School of Medicine, Kagawa, Japan

\section{Hirokazu Tanaka}

Associate Professor, Department of Perinatology and Gynecology Kagawa University School of Medicine, Kagawa, Japan

\section{CORRESPONDING AUTHOR}

Toshiyuki Hata, Professor and Chairman, Department of Perinatology and Gynecology, Kagawa University School of Medicine, 1750-1 Ikenobe, Miki, Kagawa 761-0793, Japan, Phone: +81-(0)87-891-2174 Fax: +81-(0)87-891-2175, e-mail: toshi28@med.kagawa-u.ac.jp 